\title{
Pensamentos sobre a vivência da privacidade no Facebook
}

\author{
Thoughts on privacy experience in Facebook \\ Reflexiones sobre la experiencia de la privacidad en Facebook \\ Eliane Cristina de Freitas Rocha ${ }^{l}$ \\ Camila de Fátima Pereira ${ }^{2}$
}

\section{Resumo}

Este artigo problematiza a vivência da privacidade no Facebook por meio de discussões teóricas e filosóficas (com destaque para Arendt, Huizinga e Bauman), e por estudo exploratório com análise de dados empíricos coletados entre usuários da ferramenta por questionários e entrevistas. Procurou-se entender tal vivência pela maneira como os usuários se colocam no espaço de visibilidade pública do Facebook. A empresa Facebook tem amplo acesso aos dados publicados pelos usuários, mas não os compartilha de maneira individualizada. Usuários adotam medidas contraditórias para protegerem sua privacidade: embora eles queiram preservar a intimidade por meio de autocensura, eles não são conscientes do uso que o Facebook faz de seus dados e não têm absoluto controle da visibilidade de seus perfis e postagens.

\begin{tabular}{|c|c|}
\hline & \\
\hline & \begin{tabular}{c|l}
\multicolumn{2}{c}{ Acesse este artigo online } \\
QR CODE: & Website: \\
四扬口 & http://www.revistas.ufg.br/index.php/ci
\end{tabular} \\
\hline & $\begin{array}{l}\text { DOI: } \\
\text { http://dx.doi.org/10.5216/ci.v20i2.39218 }\end{array}$ \\
\hline
\end{tabular}

Palavras-chave: Facebook. Privacidade. Visibilidade.

This paper discusses privacy experience in Facebook through theoretical and philosophical perspectives (highlighting Arendt, Huizinga and Bauman) and through exploratory research with analysis of empirical data collected by questionnaires and interviews among users of that tool. It was approached that experience investigating how Facebook users act on its public visibility space. The corporation Facebook has broad access to data posted by users but does not share individualized data from them. Users adopt contradictory measures to protect their privacy: despite they want to preserve their intimacy through self censorship, they are not aware on how Facebook use their data and do not have absolute control on the visibility of their profile and posts.

Keywords: Facebook. Privacy. Visibility.

\section{Resumen}

Este artículo problematiza la privacidad en Facebook a través de las discusiones teóricas y filosóficas (especialmente Arendt, Huizinga y Bauman), y por estudio exploratorio con análisis de datos

\footnotetext{
${ }^{1}$ Professora da Escola de Ciência da Informação da UFMG. Doutora em Ciência da Informação (UFMG) e Mestra em Comunicação Social (UFMG). E-mail: prof.lili.rocha@gmail.com.

2 Bacharel em Sistemas de Informação, Pontifícia Universidade Católica de Minas Gerais. E-mail: cacafpereira@gmail.com.
} 


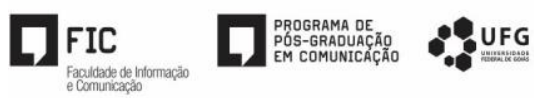

empíricos recogidos entre usuarios de la herramienta por cuestionarios y entrevistas. Se abordó esa vivencia investigando cómo actúan los usuarios de Facebook en ese espacio de visibilidad pública. La empresa Facebook tiene un amplio acceso a los datos enviados por los usuarios, pero no las acciones de manera individualizada. Los usuarios adopten medidas contradictorias para proteger su privacidad: a pesar de que quieren mantener la privacidad a través de la autocensura, no son conscientes del uso que Facebook hace de sus datos y no tienen control absoluto de la visibilidad de sus perfiles y puestos.

Palabras clave: Facebook. Privacidad. Visibilidad.

\section{INTRODUÇÃO}

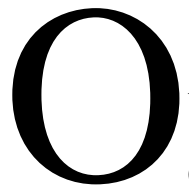

Facebook é a rede social mais popular do mundo, considerado seu número de usuários (estimados em 1.3 bilhão de usuários ativos no final de 2013, ITU, 2014) e alcance geográfico, administrada por uma empresa comercial homônima. Os usos da ferramenta, tendo em vista a própria dinamicidade da malha social nela e por ela constituída - são diversificados e podem ser compreendidos em quatro grandes categorias (ROSA; SANTOS, 2013): a- Interação Mediada: permite que os nós se relacionem entre si por meio de funcionalidades como postagem e troca de mensagens; $b$ - Ativismo: permite que os usuários se mobilizem em torno de ideais políticos tanto da política formal ou não, acompanhando a lógica dos movimentos sociais contemporâneos; c- Publicidade pessoal/profissional; d- Relacionamentos: usuários procuram manter ou construir laços afetivos.

As ameaças à privacidade dos usuários da rede social Facebook têm se tornado ponto de discussão importante para as pesquisas associadas aos fatores humanos do uso da tecnologia da informação, dada a característica fundamental da ferramenta de exposição do indivíduo no ciberespaço (visibilidade pública) e às implicações de tal exposição (ROSA; SANTOS, 2013), incluindo a problemática da regulamentação privada dos espaços de visibilidade pública.

Uma busca realizada em periódicos de excelência qualificados pela CAPES nos extratos A1 e A2, no mês de junho de 2017, na área de Comunicação e Informação - tendo sido pesquisada a palavra-chave "privacidade" nos periódicos "Transinformação", "Perspectivas em Ciência da Informação", "Informação \& Sociedade”, "Comunicação, Mídia e Consumo", "Em Questão", "Encontros Bibli", "Galáxia", "Informação \& Informação", "Revista Intercom", "Matrizes" e "Revista FAMECOS", e-Compós - possibilitou a recuperação de 31 artigos, dezessete deles na revista Matrizes, o que revela a importância e emergência do assunto privacidade, em especial na área de Comunicação Social. Um de tais 


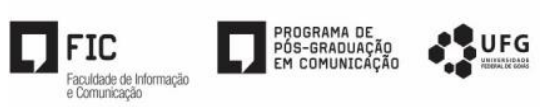

artigos, por estar precisamente relacionado com o foco desta comunicação, foi apropriado e citado nas referências bibliográficas deste estudo (LIVINGSTONE, 2012).

Desta forma, este artigo busca entender a vivência da privacidade pelos usuários da ferramenta por meio da abordagem de três aspectos envolvidos nesta questão: 1- a constituição do Facebook como ambiente público/espaço público; 2- a regulamentação privada do espaço de visibilidade pública (políticas de dados do Facebook); 3- as táticas, apropriações e vivências dos usuários ao lidarem com este espaço e com sua regulamentação. Para percorrer estes três pontos, a abordagem metodológica deste trabalho incluiu reflexões teóricas fundamentadas no trabalho de importantes pesquisadores e filósofos (com especial ancoragem na obra de Hannah Arendt, 1993; Huizinga, 2004 e Bauman, 2010), apresentada no tópico 2 deste artigo; leitura da regulamentação da política de privacidade da ferramenta com respectiva análise de seu conteúdo, conduzida no tópico 3; e, por fim, apresentação de resultados de pesquisa exploratória empírica junto a usuários do Facebook sobre os seus usos da ferramenta e a maneira com que percebem e lidam com as questões relativas à privacidade (saber como os usuários se portam nas redes sociais, como lidam com a própria privacidade e o que cada um considera ser perda de privacidade) no tópico 4, seguida de considerações finais, no tópico 5.

\section{O FACEBOOK COMO ESPAÇO PÚBLICO}

O homem contemporâneo vive o seu cotidiano tanto no espaço concreto quanto no ciberespaço. O Facebook é um destes espaços digitais onde ser realizam relações entre pessoas. Trata-se de um espaço público no sentido de um espaço de visibilidade pública, de espaço comum de convivência entre os homens, mas não no sentido do espaço de domínio estatal (THOMPSON, 1998). O Facebook é um espaço público privatizado, por ser um espaço de convivência (visibilidade pública) regulado por uma empresa comercial, ao mesmo tempo em que é tomado por propriedades privadas (perfis de pessoas físicas e jurídicas que lá se estabelecem e controlam relativamente sua fração de bits neste ciberespaço).

É no sentido do espaço público enquanto espaço de convivência entre as pessoas que normalmente se coloca a problemática da privacidade. Antes da emergência dos meios de comunicação modernos, os espaços de exposição do indivíduo ao público eram limitados pela espacialidade concreta, como a que se estabelecia nas igrejas e ruas (THOMPSON, 1998). Arendt (1993) problematiza que o espaço privado (a esfera privada), na antiguidade, era o reino da necessidade, da privação da liberdade, do exercício do labor (ligado às necessidades 


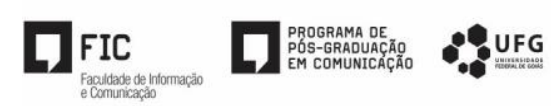

do corpo) e dos negócios humanos (tendo a economia agrária como base); enquanto o espaço público (da pólis) era o reino da dignidade e realização humana, onde o homem poderia deixar a sua marca, por meio do discurso e da ação - era o espaço político ocupado por cidadãos livres (escravos, mulheres e crianças não eram contemplados).

Com a modernidade, Arendt (1993) e Huizinga (2004) concordam que a vida humana é dominada pelo utilitarismo, que passaria a balizar a atividade política por critérios de eficiência e eficácia (ARENDT, 1993), os quais levam à perda do espírito esportivo, ao acirramento de sectarismos e à procura por divertimentos vulgares e sensacionalistas (HUIZINGA, 2004).

Dada a regulamentação da esfera privada - entendida como o reino dos negócios humanos, como os comerciais - pelo Estado, o refúgio para o homem, na modernidade, se situa na vivência da intimidade, no pensamento de Rousseau (ARENDT, 1993). Para Baumam (2010), existe uma tendência à dissolução de interesse pela vida pública política com o fim da modernidade e o ingresso em uma sociedade pós-industrial, sendo crescente o interesse do público na vida privada como se pode notar em programas de televisão cuja temática é espetacularizar o cotidiano e a intimidade (que encontra no Brasil suas manifestações nas edições do programa televisivo Big Brother Brasil, por exemplo). Esta tendência pode ser explicada pela própria conversão do espaço público da política para questões outrora privadas (como a propriedade e a vida dos indivíduos): como manifestar-se sobre questões de interesse comum onde o que se discute é o interesse privado, dos negócios humanos? A busca do espaço de visibilidade pública (o espaço comum) parece se voltar para a publicização do íntimo como uma realização humana: o homem quer deixar sua marca no espaço comum/público não pelo discurso e ação ou por aquilo que permanece (como a obra de arte), mas pela espetacularização de si, tendência que também pode estar associada ao caráter competitivo existente antes mesmo do processo civilizatório (HUIZINGA, 2004).

O conceito normativo da privacidade - "são invioláveis a intimidade, a vida privada, a honra e a imagem das pessoas, assegurando o direito a indenização pelo dano material ou moral decorrente de sua violação" (BRASIL, 1988) - considera-a praticamente como defesa da visibilidade da pessoa - a pessoa deve administrar a própria imagem e a vivência da intimidade. Nota-se a tendência em se considerar a visão intimista do conceito de privacidade em Rousseau (voltada para a proteção da intimidade). Para Ethan Katsh citado por Melo (2006), a privacidade é a capacidade de administrar o que pode ou não ser visto pelas outras pessoas a nosso respeito. Gill et al. (2011) acrescenta que a privacidade gira em torno dos 


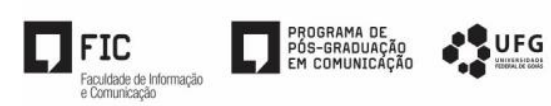

costumes das pessoas, vivência familiar e comportamentos perante a sociedade e vai de acordo com que o que cada indivíduo pensa ser exposição ou não, aspecto também apontado por Nissenbaum citado por Barkhuus (2012) que relaciona a privacidade aos costumes humanos regidos por normas éticas e culturais. Segundo Paesani (2012), direito à privacidade tem como fundamento a defesa da personalidade humana contra invasões, o que vai de encontro com a expansão de novas técnicas de comunicação, que colocam as pessoas em exposição constante.

Por outro lado, a defesa da intimidade é relativa. A abertura da vida íntima pode acontecer deliberadamente, como uma reação ao isolamento crescente dos indivíduos nas megalópoles, o que levaria ao desenvolvimento de relações interativas como presença reconfortante, no entendimento de Ferraz (2001). Também o anonimato dos espaços urbanos pode levar à busca da identidade individual, da notoriedade do nome (aspecto que faria parte da natureza humana, HUIZINGA, 2004), obtida cada vez mais pela presença nos meios de comunicação (anteriormente de massa e, atualmente, interativos). Talvez, os usuários das redes sociais estejam dispostos a expor suas informações pessoais por tais razões, embora a tendência à intimização da vida social não beneficie a sociabilidade em si, pois a invasão da vida privada íntima volta os indivíduos para si mesmos: quanto mais intimista é a comunidade, menos sociável ela é (BAUMAN, 2010). Hannah Arendt (1993) já alertava que a experiência íntima da dor é incomunicável.

Segundo Bauman (2010), a contínua exposição do sujeito a olhares vigilantes de outros significa perda de liberdade. Ao se sentir exposto continuamente, o indivíduo tende a ajustar seu comportamento para obter aprovação de seus observadores, ajustamento tal que se alinha com a metáfora do prisioneiro em um panóptico (SILVA, 2000) - modelo de prisão circular idealizado por Bentham no qual um sentinela é capaz de observar todos os prisioneiros, os quais, por terem a consciência de serem sempre vigiados, ajustariam suas condutas às normas do presídio.

Ao se considerar os conceitos de liberdade discutidos por Gomes (2002), inspirados na obra da filósofa Hannah Arendt (1993), a liberdade de colocar a vida íntima sob vigilância não é, efetivamente, liberdade nem no sentido político (liberdade de ação no espaço público com autonomia para tratar de questões de interesse público e não de interesse privado/íntimo, liberdade para criar novas premissas de ação), nem no sentido individual (haja vista a subserviência aos formatos e padrões quase inquestionáveis dos sistemas sociais e seus dispositivos, e a dificuldade de estabelecer um refúgio do mundo comum). Por outro lado, a 


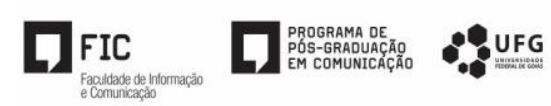

liberdade no sentido de exercício lúdico da criatividade (vislumbrada pelo pensamento de HUIZINGA, 2004), da não seriedade, também é ameaçada pelo enrijecimento das regras e normas sociais impostas pelo mercado e cristalizadas pelos dispositivos técnicos.

Há subjetividade na vivência da privacidade. O uso dos meios digitais de comunicação como das redes sociais coloca as pessoas em constante interação em um espaço de ampla visibilidade pública e modifica seus costumes relativos à exposição pessoal e seus valores relativos à privacidade (LIVINGSTONE, 2012; RECUERO, 2009; ROSA; SANTOS, 2013). O espaço privado e o espaço de visibilidade pública constituem-se como faces de uma mesma moeda, a grosso modo. Para realização da intimidade, é preciso existir a constituição do espaço público - se tudo se torna público, qual é o sentido da privacidade? Ao mesmo tempo que as pessoas podem ansiar pela preservação da intimidade (a liberdade no sentido intimista, individual), podem também abrir mão dela para se autopromover na ilusão da inscrição de sua marca no mundo corroído pela perecibilidade. Sem permanência das coisas no mundo, os indivíduos se consomem, vendem suas imagens e sua intimidade, mas sem ganhar a imortalidade ou a notoriedade. Por outro lado, a ampliação dos espaços públicos virtuais (enquanto espaços de convivência comum) potencializa a construção de fóruns de debates no sentido de construção da liberdade política com expressões de ativismo político (ROSA; SANTOS, 2013). Diante da própria modificação dos espaços de exposição pública, também muda a forma com que as pessoas podem lidar com a própria imagem e como percebem as imagens dos outros (THOMPSON, 1998). Na contemporaneidade, o que representa a privacidade num mundo em que o espaço público (de visibilidade pública) está cada vez mais voltado à vida privada (inclusive íntima) dos indivíduos?

Será que os sujeitos usuários do Facebook têm noção de que se encontram num mecanismo potencialmente panóptico? Sabem o que a ferramenta armazena de seus dados? Como desejam vivenciar sua privacidade - vêem com bons olhos a exposição pessoal, procuram refugiar-se, proteger-se? De que maneira o espaço social de visibilidade pública do Facebook é constituído e vivenciado pelos seus usuários?

Viesenteiner (2013), em uma leitura de Nietzsche sobre a vivência, a compreende como associada a três aspectos (2013): 1) conexão com a vida, com o imediato da experiência concreta; 2) significabilidade para o contexto da vida; 3) extrapolação da racionalidade na relação sujeito-mundo. A vivência da privacidade, neste aspecto, deve ter como ponto de partida as experiências de uso da ferramenta no cotidiano e nas relações concretas dos 
sujeitos, como elas são significadas por eles e como elas tocam o sujeito não apenas de forma racional.

Para endereçar as questões deste estudo de como os usuários se apropriam do Facebook e, nesta apropriação, vivenciam o Facebook como espaço de visibilidade pública, deve-se lançar mão de abordagens qualitativas que procuram entender este espaço e os sujeitos que nele habitam. As técnicas quantitativas não permitiriam alcançar os universos de significação da experiência do usuário, e por conseguinte, a compreensão de suas vivências.

\section{REGRAS OU POLÍTICAS DE PRIVACIDADE DO FACEBOOK: MODOS DE FUNCIONAMENTO DO PANÓPTICO OU AS CONDIÇÕES DO EXERCÍCIO DA LIBERDADE VIGIADA DE SEUS USUÁRIOS}

Conforme a política de uso dos dados de usuários do Facebook (FACEBOOK, 2013), válida desde 15 de novembro de 2013 até a finalização das entrevistas realizadas na pesquisa, a ferramenta coleta vários dados dos usuários: dados pessoais que são solicitados assim que é realizado o cadastro como nome, telefone (opcional), data de nascimento e e-mail; dados compartilhados pelo usuário como fotos, vídeos, atualização de status, comentários em publicações de amigos, marcações de localização, páginas curtidas e relacionamentos, os quais têm visibilidade aos outros usuários controlada pelo usuário (exceto para os dados de nome, imagens de perfil e foto de capa, redes de amigos, sexo, nome e id do usuário que são itens de visibilidade pública para qualquer internauta, usuário ou não da ferramenta). $\mathrm{O}$ Facebook também coleta dados de um usuário específico por suas conexões (como fotos marcadas, comentários com menções/marcações) e dados de uso (momento de interação com a ferramenta e funcionalidades acionadas - como postagem de fotos e vídeos, acesso a páginas/percursos realizados, como compra realizada através da ferramenta) e de localização (número de telefone de origem, ip de rede, serviços de internet, sistema operacional, localização dos usuários através de GPS e a identificação, por algoritmos, de contatos próximos).

\subsection{O problema da visibilidade constante do indivíduo (ausência de refúgio ou perda de}

\section{liberdade em nível individual)}

A mera coleta dos dados (como os que são coletados indiretamente por conexões do usuário), bem como a visibilidade pública da lista de amigos (e outros itens como foto de perfil e de capa) é indicativa da falta de privacidade do usuário - ou controle sobre os dados e 


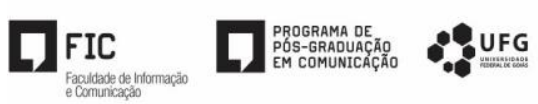

sua imagem, no sentido normativo da privacidade e associado à vivência da intimidade. $\mathrm{O}$ Facebook funcionaria como um grande catálogo de pessoas com seu respectivo círculo social para qualquer habitante do ciberespaço acessar livremente. Tal catálogo é utilizado pela empresa para realização de mídia push - distribuição de mensagens/propagandas customizadas e personalizadas diretamente às pessoas sem que elas as procurem - e pode ser visto como realização da agressividade do mercado para invasão do ciberespaço pessoal do usuário.

O Facebook não identifica individualmente seus usuários, o que representaria violação completa da privacidade em seu sentido normativo, mas possui vários produtos que ajudam os anunciantes encontrar pessoas, e utiliza cookies e pixels alegando interesse de tornar o acesso do usuário mais rápido. Quando o usuário acessa um jogo ou site, usando sua conta do Facebook (login social), são fornecidos para os aplicativos solicitantes as informações básicas dos usuários que são consideradas públicas, inclusive a lista de amigos. Ao acessar o aplicativo pela primeira vez, o Facebook fornece alguns dados (como idioma e idade) para a empresa parceira. Assim, poderão ser exibidos conteúdos de acordo com a idade dos usuários, por exemplo. Quando a conta é excluída, a empresa que fornece o aplicativo ainda poderá ter informações do usuário caso algum amigo compartilhe informações sobre ele, o que compromete a privacidade - os aplicativos também têm acesso ao conteúdo tornado público de qualquer usuário e ele não tem controle sobre isso. Para que os aplicativos não tenham informações sobre os usuários, é necessário desativar todos os aplicativos na plataforma Facebook.

Aqui se observa que a vivência da intimidade (um sentido da privacidade em Rousseu, comentada por Harendt (1993), de refúgio do indivíduo, emergente na modernidade) é ameaçada pela esfera privada dos negócios comerciais - aspecto ainda mais acentuado pelas características sofisticadas de customização de anúncios comerciais direcionados especificamente para cada usuário da ferramenta.

\subsection{O problema da publicização mercantilizada da vida privada (espetacularização e mercantilização de relações humanas) e o potencial de mobilização política das redes.}

O usuário pode, também, utilizar a ferramenta para se promover. Há mecanismos para criação de páginas para empresas, colocação de anúncios comerciais e outros que permitem a ocupação do espaço comum da rede social por empresas e pessoas. Este espaço de visibilidade pública tem sido apropriado pelo Mercado e, também, pelos indivíduos. As 


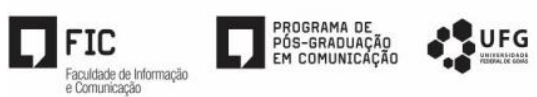

apropriações, tanto pelo mercado quanto pelos indivíduos, podem se dar de maneira espetacularizada e mimetizada (como acontece no fenômeno do espalhamento incontrolável de memes - imagens - e vídeos chocantes). Por outro lado, o potencial de mobilização das pessoas por meio do Facebook também se faz presente (ROSA; SANTOS, 2013), seja canalizado para expressão da vivência da Política quanto para vivências lúdicas (como no caso dos flash mobs).

\subsection{O problema da perda da privacidade no sentido normativo}

Não há efetivo controle, pelo usuário, do que é divulgado a seu respeito. Se, no Facebook, o usuário escolher publicar dados apenas para seus amigos/contatos e marcar um de seus amigos/contatos na publicação, todos os amigos daquele amigo marcado conseguirão visualizar a publicação, o que compromete a privacidade, afinal, a pessoa marcada não tem controle sobre a sua informação que está circulando - um terceiro pode saber de você pelo que o outro amigo publicou. Mesmo que o usuário não permita que a publicação em que ele apareça marcado circule (denunciando, por exemplo, ou, controlando o que imediatamente vai estar visível no seu perfil/linha do tempo), outros usuários podem copiar, compartilhar, comentar publicações sem que o indivíduo tenha controle sobre isso. É claro que na vida em sociedade é impossível uma pessoa controlar tudo que é falado a seu respeito, mas a facilidade e a velocidade com que a disseminação de dados pessoais acontece na rede e suas repercussões são de alcance quantitativa e qualitativamente também grandes para serem negligenciados.

\section{EXPLORANDO VIVÊNCIAS DOS USUÁRIOS DO FACEBOOK}

Pensar Até este tópico do artigo, o estudo da vivência da privacidade no ciberespaço social do Facebook foi essencialmente orientado pelo olhar ciência social conjugado ao da filosofia, visando construir a compreensão do fenômeno de uma perspectiva complexa. Tal perspectiva não reduz a explicação dos fenômenos à coleta e análise de dados empíricos e encoraja a triangulação de técnicas de pesquisa. Para este trabalho, tal triangulação se deu pelo emprego de duas técnicas de coleta de dados: aplicação da técnica de questionário; realização de entrevista estruturada.

O questionário aplicado conteve 31 questões fechadas referentes a dados pessoais (sexo, idade, profissão, escolaridade), ao uso do aplicativo (frequência de uso, característica dos dados postados) e sobre a vivência da privacidade (visibilidade do perfil, problemas de 


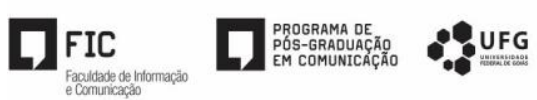

invasão de privacidade, conhecimento da visibilidade das publicações). Sua aplicação se deu no período de abril de 2014 e, embora o questionário seja uma técnica de coleta de dados quantitativa, não foram utilizadas estatísticas inferenciais avançadas para a análise dos dados, já que a amostra de respondentes foi de conveniência e não probabilística (GONZÁLEZTERUEL; BARRIOS-CEREJÓN, 2012). O cabeçalho do questionário continha explicações sobre a pesquisa e garantia sigilo dos participantes, com termo de consentimento incorporado.

Como se procurava entender as vivências da privacidade pelos sujeitos, foi preciso entrar em contato diretamente com eles para esclarecer o fenômeno, o que é possível com o emprego de técnicas qualitativas de coleta de dados (GONZÁLEZ-TERUEL; BARRIOSCEREJÓN, 2012). Para este fim, foi realizada uma entrevista estruturada junto a usuários da ferramenta, no período de outubro a novembro de 2014, que lançou mão de questões referentes a dados pessoais (sexo, idade, escolaridade, profissão), outros referentes a uso do aplicativo (frequência de uso) e específicas sobre privacidade, as quais foram redigidas de uma perspectiva compreensiva (MINAYO, 2010), para saber os significados atribuídos pelos sujeitos à privacidade, incluindo o uso da técnica do incidente crítico (PEREIRA et al., 1980), com o relato de casos reais vivenciados de perda de privacidade. Os usuários foram informados da pesquisa e consentiram participar com a garantia do seu anonimato. Oito pessoas foram entrevistadas nesta etapa da pesquisa, que procurou observar o ponto da saturação informativa - quando nenhuma outra informação é acrescentada às já coletadas na entrevista (GONZÁLEZ-TERUEL; BARRIOS-CEREJÓN, 2012). A técnica de tratamento dos dados da entrevista foi a análise de conteúdo com enfoque indutivo (GONZÁLEZTERUEL; BARRIOS-CEREJÓN, 2012), o qual consiste na atenta leitura do material com identificação de categorias analíticas para as respostas às questões.

A apresentação dos resultados da coleta de dados empírica e sua análise será realizada em conjunto na seção seguinte, alternando-se os dados quantitativos e qualitativos e sua explicação, fundamentada tanto nas falas e vivências dos usuários, quanto nas reflexões teóricas e bibliográficas apresentadas nas seções anteriores.

\subsection{Resultados: o Facebook vivenciado pelos seus usuários}

Um questionário foi criado, disponibilizado e distribuído online para a lista de contatos de e-mail e conexões do Facebook das pesquisadoras por um período de 16 dias - de 9 a 24 de abril de 2014 -, contando com a participação de 57 usuários. As características gerais dos respondentes são: a- quanto à faixa etária: nenhum idoso está presente, a faixa 
predominante é de 18-25 anos (52,3\%), seguida da faixa de 26 aos 33 anos $(22,8 \%)$ e das faixas de 34 a 41 anos (14\%), de 42 a 49 (7\%). As demais faixas representam 5,26\%; bquanto ao sexo: 45,3\% eram do sexo feminino e 54,7\% eram do sexo masculino ; c- quanto ao estado civil: solteiros são a maioria $(66,6 \%)$ seguido pelos casados $(28,1 \%)$; d- quanto à escolaridade: os respondentes com ensino superior incompleto são maioria $(52,6 \%)$, seguidos do superior completo $(22,8 \%)$, fundamental completo e incompleto $(10,5 \%)$, médio completo e incompleto $(8,8 \%)$, pós-graduados $(5,3 \%)$. O perfil geral dos respondentes aproxima-se do perfil de usuários geral da ferramenta no que diz respeito ao fato de a faixa etária dos utilizadores ser predominantemente jovem (ZEPHORIA, 2014).

$\mathrm{Na}$ amostra pesquisada, observa-se que cerca da metade dos entrevistados acessa o Facebook várias vezes ao dia $(54,4 \%)$. Outros $15,8 \%$ acessam a plataforma ao menos uma vez ao dia. O tempo de conexão predominante é de até 30 minutos por acesso $(65,31 \%)$. Tal perfil é similar ao já apontado por Pereira Júnior e outros (2013) e compatível com o apontado em pesquisas internacionais (que indicam que o tempo de conexão é na faixa de 20 minutos, ZEPHORIA, 2014). A maior parte dos participantes respondentes do questionário acessa o Facebook por celular $(75,9 \%)$ e/ou por computador ou notebook $(79,6 \%)$. O acesso por ambos dispositivos é indicativo da importância da conexão constante com a rede, e de que o Facebook já faz parte do dia a dia das pessoas.

Além do levantamento por questionário, também foram realizadas oito entrevistas estruturadas, no período de outubro a novembro de 2014, com o objetivo de entender o significado social do uso do Facebook e a percepção da privacidade por seus usuários. A seguir (Quadro 1), pode ser verificado o perfil dos participantes entrevistados, onde se observar, na quarta coluna, a quantidade de conexões (contatos, amizades), seguida por barras da quantidade de contatos conhecidos e separada por uma linha dos contatos com que a pessoa convive. Dos participantes, todos são solteiros, exceto Usu4 e Usu8 (única que tem filhos); e acessam a ferramenta com frequência (mais de um acesso na semana), exceto Usu2, a qual acessa raramente.

Quadro 1 - Participantes da pesquisa entrevistados

\begin{tabular}{c|l|l|l|l} 
Entrevistado & Sexo & Idade & Escolaridade & Conexões/Conhece/Convive \\
\hline Usu1 & M & 18 & Médio incompleto & $900 / 800 / 100,150$ ou 200 \\
\hline Usu2 & F & 18 & Médio incompleto & $200 / 150$ a170/ 150 a 170 \\
\hline Usu3 & M & 40 & Superior completo & $700 / 600 / 150$ \\
\hline Usu4 & M & 27 & Superior completo & $200 /$ Próximo de 200/50 \\
\hline Usu5 & F & 28 & Superior completo & $310 / 240 / 90$ \\
\hline
\end{tabular}




\begin{tabular}{l|l|l|l|l}
\hline Usu6 & M & 25 & Superior incompleto & $300 / 200 / 50$ \\
\hline Usu7 & F & 24 & Superior incompleto & $380 / 350 / 38$ \\
\hline Usu8 & F & 56 & Médio completo & $20 / 15 / 15$
\end{tabular}

Fonte: elaborado pelas autoras.

\subsection{Controle sobre os dados e visiblidade}

No sentido normativo da privacidade, é necessário que o usuário tenha controle sobre seus próprios dados e, este controle, no Facebook é relativo, o que permite categorizar a ferramenta como invasora de privacidade. Parcialmente o usuário pode controlar a visibilidade dos seus dados, mas não tem condições de bloquear a disseminação de alguns deles (os dados públicos) completamente, a menos que deixe de usar o aplicativo. Mas, será que os usuários estão conscientes de como seus dados são disseminados? O que se sabe, por revisão de literatura, é que os usuários do Facebook mostram preocupação com sua privacidade (entendida como proteção de dados que não querem consentir públicos), mas não dominam o que o dispositivo oferece para controle de dados: Pereira Junior e outros (2013) indicam claramente, por trabalhos empíricos, que há dificuldades de os usuários identificarem as consequências causadas em não estarem atentos às configurações de publicação de dados, como fotos, apontando que eles imaginam, entre outras questões, que, ao publicar uma foto para os "amigos" e marcando-os na foto somente os amigos verão, quando se sabe que também os amigos daquele amigo têm acesso àquela informação. Esta constatação da falta de consciência do usuário sobre o controle da visibilidade de suas postagens também aparece nos resultados do questionário aplicado, onde se nota que, em resposta à pergunta "Quando marcamos um amigo em uma publicação, quem pode ver?", a resposta dada pelos participantes foi: 53,8\% amigos; 21,20\% amigos e amigos de amigos; 5,8\% amigos de amigos; $11,5 \%$ todos; $7,7 \%$ não sabe. Tal variação na resposta e alto índice erros é ainda mais impressionante quando se constata que dos usuários que afirmaram ter lido a política de privacidade do Facebook ( 8 dos 57 respondentes, ou 14\%) nenhum deles deu a resposta correta. $\mathrm{O}$ desconhecimento da política de privacidade do aplicativo (entendida pelo Facebook como política de dados) também já tinha sido evidenciada em Pereira Júnior e outros (2013). Os entrevistados, por sua vez, vacilam quando perguntados sobre quem vê o seu perfil e seus dados postados. Apenas um deles adotou uma medida de fechamento do perfil para visualização de amigos (Usu2), cinco deles afirmam selecionar a visibilidade das postagens, Usu3 diz saber quem tem acesso aos seus dados, apesar de seu perfil ser aberto, e dois deles 


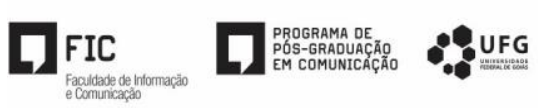

(Usu1 e Usu8) evidenciam perda de controle de visibilidade: "[o perfil fica] nu pra muita gente, pra muita gente, Nossa Senhora. Quem dera fosse só pro meus amigos, né, mas quem controla a internet tem acesso a essas informações. Bem, eu acho. [...] porque se você entrar no Facebook de outra pessoa que não seja trancado, privado, você consegue ver as coisas das pessoas, aí os dados das outras pessoas, mesmo não sendo suas amigas, eu acho isso errado" (Usu1).

Apesar de considerar "errado", o mesmo entrevistado considera que o Facebook pode usar os dados para indicar anúncios comerciais.

Notou-se, nas entrevistas, que os usuários são confusos quanto à efetiva visibilidade dos seus dados. Pelo comportamento despreocupado acerca de quem vai ter acesso ou não aos dados de perfil e publicados, há perda de privacidade no sentido da perda de controle dos dados sobre si, a qual é acentuada quando se sabe que os dados de visibilidade pública são acessíveis a qualquer internauta e a parceiros comerciais do Facebook.

Outro ponto importante quanto ao controle dos dados é que os usuários entrevistados não estão certos sobre quais dados o Facebook tem acesso e compartilha (aspecto também apontado por Pereira Júnior e outros (2013)): Alguns pensam que são somente os dados públicos de perfil cadastrados (Usu3, Usu5); outros afirmam que são todos os dados, incluindo os postados (Usu1, Usu2, Usu4, Usu8) e as fotos (Usu6); outros dizem que todos, desde que consentidos pelo usuário (Usu3, Usu7). Um deles problematiza que tipo de dado pode ser compartilhado e sua destinação para a publicidade: “Tipo, é igual por exemplo, ter dado do seu e-mail, eles podem compartilhar pra fazer anúncio pra outros negócios, igual por exemplo, cê tá querendo comprar um tênis e cê entra num site aí cê vai no seu e-mail e fica aparecendo anúncio de tênis do site que cê entrou, isso é informação compartilhada, se não não tem como eles saberem" (Usu1).

A falta de conhecimento do destino dos dados pessoais pela ferramenta não é impeditivo para seu uso e a perda da privacidade é encarada como um risco calculado: "nas cláusulas que a gente não lê, isso tá lá [o que o Facebook faz com seus dados], e mesmo assim só por querer ter a gente aceita correr o risco porque a gente acha que nada nunca vai acontecer com a gente" (Usu2).

Metade dos usuários entrevistados dizem não conhecer a política de privacidade do aplicativo (Usu5, Usu6, Usu7, Usu8), por não se interessarem por ela ou por se autocensurarem nas postagens. Dos demais, um acredita que existe uma censura do próprio 


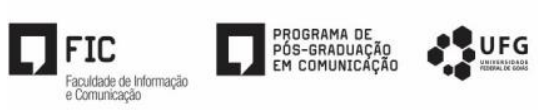

aplicativo, outro diz que a ferramenta pode usar fotos e dados e outros dizem parcialmente conhecer alguns termos.

Chama atenção, nas falas, que há falta de conscientização quanto à importância de se saber o que é compartilhado pela empresa Facebook. As pessoas concordam tacitamente em serem objetos do sistema automático da rede social, que está a vigiar seus passos. O risco deste comportamento é a sua naturalização, já que a falta de problematização da importância de ter o controle sobre seus próprios dados pode representar a perda da autonomia, do exercício da liberdade individual: se a pessoa não se vê como responsável por seus dados, mas delega naturalmente suas informações, ele se coloca como presa do sistema da rede social, ela deliberadamente se deixa vigiar. A metáfora para este comportamento é a dos ratos de laboratórios: as pessoas se colocam em um local de experimentação comercial passivamente, são objetos de cálculo (perda da liberdade individual, conforme debatida no tópico 2 deste artigo) e não têm o poder (nem o interesse) de estabelecer as regras daquele espaço, já que elas não são postas à discussão (perda de liberdade política, também debatida no tópico 2). Esta quase impossibilidade de questionamento das regras envolvidas no uso dos dados pela ferramenta é indicadora de totalitarismo - traço associado à violência da imposição da técnica na vida em sociedade que adquire contornos da vivência da dromocracia cibercultural: "O ideal cínico da cibercultura é o homo dromologicus com a consciência feliz e despreocupada do homo ludens. Dessa maneira, a violência da técnica avançada adquire, de tão invisível, o ar que lhe talha a sofisticação e a imunidade que também a redime de todo questionamento público" (TRIVINHO, 2005, p.73).

Outro ponto digno de nota é que, dos usuários respondentes do questionário, há nítida perda de controle sobre os próprios dados ao se observar os seguintes indicadores: 46\% tinham mais de 300 amigos (conexões); apenas 52\% conheciam pessoalmente todos seus contatos e outros e $39 \%$ conhecem a maioria deles; $18 \%$ deixavam seu perfil aberto ao público (todos os dados abertos a qualquer internauta). O próprio desconhecimento de todos os contatos já evidencia falta de controle da privacidade por parte do usuário, constatação semelhante já tinha sido notada em Pereira Júnior e outros (2013). Há, ainda, nos questionários, o agravante de que, ao serem perguntados se convivem com os contatos, somente $3,7 \%$ dos respondentes conviviam com todos, outros $42,6 \%$ com a maioria deles e $48,1 \%$ com a minoria deles, sendo que o grau de confiabilidade desta informação é baixo pela desejabilidade social da resposta - o respondente informa dados que julga ser o correto, não necessariamente o verdadeiro. Ao se analisar, na entrevista qualitativa, se os usuários 


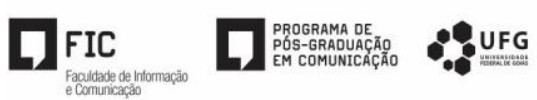

conhecem e convivem com seus amigos/contatos, nota-se que alguns não se lembram quantos amigos têm e a minoria faz parte do círculo de convivência, tal qual aconteceu na etapa quantitativa (ver QUADRO 1), além de que o grande número de pessoas de convivência é justificado pela profissão, por uma das pessoas: "uns 150 [eu convivo], porque tem aluno", indicativo de que a convivência também não representa profundidade de relações. Recuero (2009) já alertava para a artificialidade da formação das redes na internet:

Uma vez acrescido o ator, ele permanece na rede até que delete seu perfil ou seja deletado da rede. Uma vez criada a rede social, portanto, ela se manterá no tempo, independentemente da existência de interação entre os agentes, porque o sistema mantém essa estrutura. Trata-se, portanto, de uma conexão que não perde força com o tempo, o que, em se tratando de relações sociais, demonstra uma certa artificialidade nas estruturas sociais apresentadas (RECUERO, 2009, p.54).

Se o usuário quer ter controle sobre seus dados, seria necessário que ele tivesse controle sobre quem visualiza seu perfil, o que não se concretiza para a maior parte deles. Livingstone (2012) endossa a recomendação de que os usuários devem ser educados para o uso do Facebook, propondo encartes sobre bons modos nas redes sociais, além de alertar para a necessidade de se conscientizar da perda de privacidade que ocorre por meio da utilização indiscriminada de localizadores como Fousquare e Open Graph. Um dos usuários da etapa qualitativa (Usu2) se disse preocupado com os dados de localização por questões de segurança.

Assim como no estudo de Pereira Júnior e outros (2013), nos questionários, constatouse proporção pequena de usuários com problemas relativos à invasão de conta (14\%) acesso indevido de dados, invasão de conta por terceiros, recebimento de informações indevidas - a pesquisa indicou que um respondente do questionário teve problema com invasão de conta $(1,75 \%)$, sem saber especificar detalhes, enquanto outros $5(8,77 \%)$ não sabiam responder ou avaliar se tiveram problemas. $\mathrm{Na}$ etapa qualitativa, nenhum dos entrevistados relatou problemas de invasão de perfil e integridade da conta e, dos relatos de problemas de privacidade de terceiros, três indicaram os seguintes: criação de perfil falso, utilização de conta alheia por descuido e uso indevido de dados.

\subsection{Autocensura}

A normalização do comportamento ou autocensura pode ser considerada consequência natural da estrutura do panóptico. Ao saber que é vigiado, ou ter consciência da visibilidade, é 


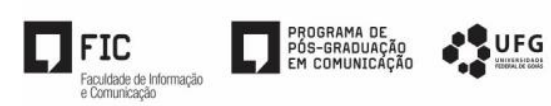

esperado que os indivíduos adequem seu comportamento às normas sociais (SILVA, 2000). Porém, como se pode perceber no tópico anterior, os indivíduos não têm plena consciência do controle que o Facebook tem sobre seus dados, e também parecem não se importar tanto com isso - era como se não tivessem consciência da vigilância e de seu alcance, de forma que talvez não precisem adequar seu comportamento. Uma das maneiras de se notar se os usuários procuram ser autovigilantes é observar o que publicam, e se procuram preservar sua intimidade.

Questionados sobre o conteúdo e natureza das informações postadas, os respondentes do questionário postam frases ou pensamentos, fotos, preferências musicais, piadas e vídeos sobre esporte, vida pessoal e citações. O uso da ferramenta para propaganda (domínio do privado invadindo o espaço público) e para divulgação de mensagens do mundo da política e correntes (exercício potencial de ativismo) é pequeno. Embora menos da metade dos respondentes do questionário tenham revelado postar dados com frequência, nota-se que eles indicam a prevalência de publicações de dados da vida pessoal e de assuntos cotidianos (esporte, citações), o que significa que a ferramenta expõe a vida privada das pessoas. Todos os usuários entrevistados endossam os resultados obtidos no questionário, como aponta Usu7: "ah, a maior parte [das postagens é] sobre a minha vida pessoal, sobre coisas do meu dia a dia, fotos pessoais, compartilhamento de notícias, e... coisas engraçadas que o Facebook tem", com exceção de uma entrevistada, mais velha, casada e com postura mais passiva de uso (Usu8): "as informações eu prefiro guardar para mim”. Os participantes da etapa qualitativa ajudam a esclarecer a natureza das informações postadas (Usu2, Usu4): “coisas relevantes, tipo de pensadores, tipo Maquiavel ou então um filme que eu gostei e falei alguma coisa sobre" (Usu2); "fotos com amigos, família" (Usu6). O uso para ativismo não é destacado nas falas, mas aparece discretamente em postagens sobre feminismo (Usu5) e na indicação de postagens de teor político apontada por Usu3.

$\mathrm{Na}$ etapa qualitativa da pesquisa, ao serem questionados sobre o uso do aplicativo, os usuários dizem que ele serve para: a) atender necessidades de informação (Usu2, Usu5, Usu8) relativos a "notícias sobre shows, sobre cidades, sobre notícias em geral, sobre entretenimento, piadas, charges, notícias sobre o Brasil, sobre o mundo"; b) entretenimento (“descanso a cabeça, desligo do mundo", Usu3) e c) manter contato social com familiares e amigos; d) ajudar nas atividades escolares ou profissionais (Usu1, Usu3, Usu7). A apropriação principal da ferramenta é "fazer coisa entre a gente, amigo mesmo" (Usu1) e "manter relações próximas com pessoas que não posso ver com tanta frequência" (Usu7), de maneira que o aplicativo é 


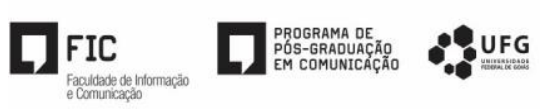

vivenciado como uma ferramenta para interação mediada entre o eu e o mundo. Portanto, os sentidos e usos da ferramenta não fogem aos já apresentados por Rosa e Santos (2013) e comentados na introdução deste artigo.

No questionário aplicado, das duas pessoas que sempre postam informações da vida pessoal, um deles tem o perfil público. É intrigante perceber que a abertura da vida privada é confirmada em outros trabalhos, como o de Livingstone (2012), que mostra como os adolescentes se portam nas diversas redes sociais, revelando que eles dividem senhas com amigos e enxergam a ferramenta como espaço de expressão pessoal e pertencimento a um grupo, mas desejam manter a privacidade no sentido de protegerem-se do olhar vigilante dos pais. Ao mesmo tempo, na etapa qualitativa, notou-se que os jovens entrevistados notam o uso da ferramenta para autopromoção. Recuero (2009) comenta que é a visibilidade é um “imperativo para a sociabilidade mediada pelo computador", o que aponta para um certo determinismo da técnica na exposição constante do indivíduo.

Embora postem muitos dados pessoais, os entrevistados da etapa qualitativa demonstraram sentimento de autopreservação, adotando uma espécie de autocensura já observada no trabalho de Pereira Júnior e outros (2013), consequência possível da natureza panóptica do dispositivo. À exceção de um entrevistado, que considera que tudo pode ser publicado na rede pelo seu caráter democrático, os participantes entrevistados dizem que há coisas que não deveriam ser publicadas: conteúdos muito íntimos, como a vida em família; relacionamento afetivo-sexual; publicações preconceituosas; informações comprometedoras de si e dos amigos (preocupação com a preservação da imagem), política, futebol: “[Não devem ser publicadas] principalmente as [informações] pessoais, as muito pessoais, as que envolvem exnamorados, ex-amigos, sentimentos, de forma geral as pessoas que fazem o Facebook ser um diário de si mesmo, ou então uma forma de fazer mal às pessoas, com coisas irrelevantes, coisas preconceituosas, coisas muito pessoais, eu acho que isso podia ser deixado de lado porque é uma gama muito grande de pessoas que usam Facebook, e nem todo mundo tem o cuidado de escolher quem é aceito, e às vezes só quer mais amigos pra ter mais status, e esquece dessa, dessa peneira aí" (Usu2).

Os entrevistados pensam no impacto daquilo que postam e acabam restringindo as publicações/postagens, para não transmitirem imagem negativa de si e dos outros ("na verdade o compartilhar é uma coisa que eu achei bacana, e não uma ferroada", Usu2), alguns querem falar coisas relevantes: "[quero] que aquelas pessoas se sintam informadas e questionadas a respeito do que elas pensam" (Usu3). 


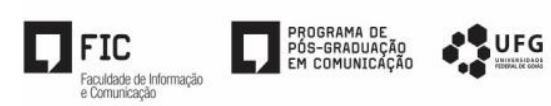

Ao serem questionados se consideram o Facebook uma ferramenta de perda de privacidade, a maioria dos respondentes do questionário $(51,92 \%)$ afirma que sim, enquanto outros $(13,46 \%)$ nunca pensaram nisso. Entre os entrevistados, duas pessoas apresentaram hesitação sobre o significado da privacidade e consideraram uma pergunta difícil, e no geral, apresentam três abordagens da privacidade:

a) a privacidade como um refúgio no espaço concreto, mas também na rede, lugar de exercício da liberdade individual no sentido de Arendt: "Acho que é não dever satisfação pra ninguém, acho que grande, a grande sacada da privacidade é essa, a partir do momento que você controla quem sabe certas coisas da sua vida e quem não sabe da sua vida, pessoal, profissional, qualquer área da vida, você tendo privacidade, você não deve dar satisfação a certas pessoas por... vários motivos" (Usu7)

b) a privacidade como a preservação das relações íntimas de ordem afetivo-sexual: um entrevistado apontou problemas vivenciados por uma pessoa que exibiu informações de conteúdo erótico e foi denunciada e xingada na ferramenta (Usu3). Outros vêem a privacidade também com este viés: “Ai, privacidade tem a ver, pra mim tem a ver com intimidade. [...] É... muito importante, por causa que algumas pessoas andam postando vídeos de sexo sem que, sem que as pessoas do vídeo saibam. Eu acho importante ter controle da sua privacidade" (Usu5). "É ótima a privacidade. É você ter o seu relacionamento sem ninguém interferir, porque se você não tiver a sua privacidade todo mundo dá palpite no que você tem que fazer, no que cê deve fazer. Então você ter a sua privacidade te garante isso né” (Usu6);

c) a privacidade como controle de dados pessoais (equivalente à visão normativa da privacidade, com preservação da integridade da pessoa, contrária a invasões do seu espaço): "Acho que é você ter autoridade suficiente pra permitir o que você quer que seja divulgado da sua vida e o que você não quer que seja divulgado da sua vida. Se você perde esse controle você não tem privacidade mais" (Usu7). "Bom, pra quem estudou publicidade, a gente praticamente não tem privacidade, seja ela em rede social ou não. Então a gente tá exposto em qualquer lugar. A gente tá cheio de olho vivo aí vigiando a gente e a gente nem sabe pra onde essas informações vão, o que é feito com elas" (Usu6).

Os entrevistados percebem problemas relativos à ausência de privacidade na ferramenta, como: 1) problemas de segurança ("porque você não pode dar acesso a pessoas desconhecidas no mundo digital a informações que podem te prejudicar. Por exemplo, dados bancários", Usu4); 2) problemas de proteção da identidade e integridade de dados pessoais ("a pessoa acabou liberando [foto] pra todo mundo, quando ela deveria ter um controle [...e] fizeram a 


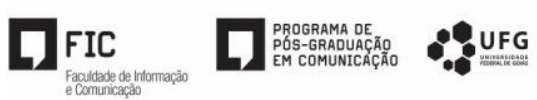

manipulação desta foto, prejudicando a pessoa no ambiente escolar", Usu5); 3) problemas de exposição da intimidade.

A percepção da privacidade dos usuários entrevistados está associada essencialmente à preservação da intimidade (com riscos para a imagem pessoal e aos relacionamentos afetivosexuais). Parece que o próprio conceito de intimidade é colocado em dúvida em duas falas contraditórias a seguir: 1) "[Tem gente que] vai no banheiro e coloca no Facebook, vai numa festa e coloca no Facebook. Hoje várias pessoas falam pra onde que vão, faz um almoço em família e coloca no Facebook... [Eu acho que não deve colocar isso] é uma coisa pessoal, é uma coisa daquele momento, você não tem que ficar compartilhando pra todo mundo. Você tem que compartilhar pra todo mundo o que todo mundo sabe o que você vai fazer. Tipo, você vai fazer um churrasco e convida vários amigos seus, aí esses amigos, aí alguns amigos não foram, você coloca uma foto da galera tirando a foto pros seus amigos e fala 'você fez falta'... tipo isso, mas uma coisa íntima sua você não precisa ficar postando pra todo mundo" (Usu1); 2) "Eu adoro ser uma pessoa anônima no Facebook como mais uma no Facebook ou no Twitter" (Usu7). Na fala 1, nota-se que a festa com os amigos pode ser considerada uma situação da vida privada, assim como a festa em família - o que faz a situação da vida privada ser considerada íntima são os destinatários, e se não se tem controle sobre eles? Já na fala 2, a pessoa anseia pelo anonimato na rede, o que é condição realizável essencialmente com a criação de perfis falsos.

\section{CONSIDERAÇÕES FINAIS}

As vivências dos usuários relativas à privacidade no Facebook - ou seja, como os usuários usam, atribuem significações e se relacionam com a ferramenta para além da mera racionalidade e utilitarismo, com fins de se colocarem em um espaço de visibilidade pública marcado pelo lúdico - não deixam dúvidas de que a privacidade destes usuários está em risco.

$\mathrm{O}$ fato dos usuários assumirem o risco da perda da privacidade em suas diversas dimensões - controle sobre os dados disponíveis sobre si; preservação da intimidade; refúgio do mundo - ainda precisa ser discutido, suscitando discussões sobre valores sociais que podem remeter a estratégias de autopromoção em um mundo espetacularizado (conforme apontado por Bauman, 2010) ou à objetificação do ser humano no ciberespaço, problematizados por autores como Trivinho (2004). O uso da rede social Facebook é um caso de inserção do homem contemporâneo imerso relações com o sistema técnico-social fora de seu controle: a perda da privacidade é um dos aspectos da perda de autonomia de si próprio 
diante da naturalização do uso de ferramentas facilitadoras de interações (sociais) humanas. Não é possível dizer não ao uso da ferramenta: Como deixar de fazer parte do mundo dos homens, de realização do espírito humano lúdico, competitivo e gregário que lá encontra espaço de manifestação?

Pertencendo a este espaço, qual é o risco da exposição de si no espaço de visiblidade pública? O risco que se corre da contínua exposição não chega a ser profundamente problematizado, pois a capacidade humana de ação e palavra (de colocar-se como autônomo num mundo constituído por ele mesmo) - parece ter subsumido pela participação (interativa) no espetáculo inebriante das coisas irrelevantes e belas da vida privada tragadas na forma de um sistema técnico digital não sujeito a contestações.

\section{REFERÊNCIAS}

ARENDT, H. A condição humana. 6 ed. Rio de Janeiro: Forense Universitária, 1993.

BARKHUUS, L. The Mismeasurement of Privacy: Using Contextual Integrity to Reconsider Privacy in HCI. In: CONFERENCE ON HUMAN FACTORS IN COMPUTING SYSTEMS, CHI'12., 2012. Proceedings... SIGCHI-ACM, Austin, Texas, USA, p. 367-376.

BAUMAN, Z. Em busca da política. Rio de Janeiro: Jorge Zahar Ed, 2010.

BRASIL. Constituição da República Federativa do Brasil. 1988.

FACEBOOK. Política de dados. 2013. Disponível em <https://www.facebook.com/full_data_use_policy> Acesso em dez 2014.

FERRAZ, M. C. F. Reconfigurações do público e do privado - Mutações da sociedade tecnológica contemporânea. In: ENCONTRO ANUAL DA ASSOCIAÇÃO NACIONAL DE PROGRAMAS DE PÓS-GRADUAÇÃO EM COMUNICAÇÃO (COMPOS), 10., 2001, Brasília. Anais... Compós, 2001.

GILL, A. J. et al. Privacy Dictionary: A Linguistic Taxonomy of Privacy for Content Analysis. In: CONFERENCE ON HUMAN FACTORS IN COMPUTING SYSTEMS, CHI 2011., 2011., Vancouver, Candada Proceedings... ACM-SIGCHI.

GOMES, J. C. L. Marcuse: tecnologia e liberdade no mundo administrado. Síntese, Belo Horizonte, v. 29, n. 93, p.237-250, 2002.

GONZÁLEZ-TERUEL, A.; BARRIOS-CERREJÓN, M. Métodos y técnicas para la investigación del comportamiento informacional: Fundamentos y nuevos desarrollos. Gijón-Asturias: Ediciones TREA, S. L.,. 2012.

HUIZINGA, J. Homo Ludens: o jogo como elemento de cultura. São Paulo: Perspectiva, 2004 ITU - International Telecomunication Union. Measuring the Information Society Report. 2014. Disponível em $<<$ http://www.itu.int/en/ITU-

D/Statistics/Documents/publications/mis2014/MIS2014_without_Annex_4.pdf >>Acesso em jan 2015. 
LIVINGSTONE, S. Oportunidades arriscadas na criação de conteúdo jovem: o uso pelos adolescentes de sites de redes sociais para intimidade, privacidade e expressão própria. Comunicação, mídia e consumo. São Paulo, v . 9 n.2 p. 91-118, ago.2012.

MELO, H.S. Comunicação mediada por computador e privacidade. 2006. Tese (Doutorado em Comunicação) - Universidade Federal do Rio de Janeiro, ECO. Rio de Janeiro.

PAESANI, L.M. Direito e Internet: Liberdade de informação, privacidade e responsabilidade Social. São Paulo: Atlas, 2012.

PEREIRA, M. N. F. et al. A aplicação da técnica do incidente crítico em estudos de usuários da informação técnico-científica: uma abordagem comparativa. In: FOSKET, D. J. et al. A contribuição da psicologia para o estudo dos usuários da informação técnico-científica. Rio de Janeiro: Calunga, 1980.

PEREIRA JUNIOR, M. P. et al. Navegar impreciso: a privacidade no facebook vivenciada por seus usuários. In: Simpósio Brasileiro de Sistemas de Informação, 9., 2013, João Pessoa. Anais... SBC: Porto Alegre, 2013.

RECUERO, R. Redes sociais na internet. Porto Alegre: Sulina, 2009.

ROSA, G. A. M.; SANTOS, B. R.. Facebook e nossas identidades virtuais. Thesaurus, 2013.

SILVA, T. T.. O panóptico. Belo Horizonte: Autêntica, 2000.

THOMPSON, J. B. A mídia e a modernidade: uma teoria social da mídia. Petrópolis: Vozes, 1998.

TRIVINHO, E. 2005. Introdução à dromocracia cibercultural: contextualização sociodromológica da violência invisível da técnica e da civilização mediática avançada. Revista FAMECOS, Porto Alegre, n.28, dez 2005.

VIESENTEINER, Jorge Luiz. O conceito de vivência (Erlebnis) em Nietzsche: gênese, significado e recepção. Kriterion, Belo Horizonte, v. 54, n. 127, p. 141-155, June 2013 . Available from $<\mathrm{http} / / / \mathrm{www}$. scielo.br/scielo.php?script=sci_arttext\&pid=S0100512X2013000100008\&lng=en\&nrm=iso>. access on 25 June 2017. http://dx.doi.org/10.1590/S0100-512X2013000100008.

ZEPHORIA. The Top 20 Valuable Facebook Statistics. Out 2014. Disponível em < https://zephoria.com/social-media/top-15-valuable-facebook-statistics/> Acesso em jan 2015. 